ISAHP Article: Mu, Saaty/A Style Guide for Paper Proposals To Be Submitted to the International Symposium of the Analytic Hierarchy Process 2014, Washington D.C., U.S.A.

\title{
ERP SOFTWARE SELECTION MODEL USING ANALYTIC NETWORK PROCESS
}

\author{
Andre Surya Lesmana, Ririn Diar Astanti*, The Jin Ai \\ Department of Industrial Engineering \\ Universitas Atma Jaya Yogyakarta \\ Yogyakarta, DIY, Indonesia \\ *E-mail: ririn@mail.uajy.ac.id
}

\begin{abstract}
During the implementation of Enterprise Resource Planning (ERP) in any company, one of the most important issues is the selection of ERP software that can satisfy the needs and objectives of the company. This issue is crucial since it may affect the duration of ERP implementation and the costs incurred for the ERP implementation. This research tries to construct a model of the selection of ERP software that are beneficial to the company in order to carry out the selection of the right ERP software vendors according to the needs and objectives of the company. The proposed ERP software selection model is constructed based on three different perspectives, that are business, technology, and organizational perspectives. Each perspective consists of various criteria needed to be considered in the selection of ERP software. The proposed model is built over four clusters, which are Business Perspective (Cost, Quality, Vendor Status, Customization), Technological Perspective (Functionality, Duration of Implementation, User Friendliness, Software Update), Organizational Perspective (Training, Employee Needs, Company Culture, Human Resistance), and Vendor Alternative (Vendor A, Vendor B, Vendor C). Since this problem of ERP software selection is involving many criteria and there exist dependency among criteria, the ERP software selection model is constructed based on the Analytic Network Process methodology. The Super Decision software used in this research for solving the model using an illustrative example from an automotive finance company in Indonesia.
\end{abstract}

Keywords: Analytic Network Process, Multi Criteria Decision Making, Enterprise Resource Planning, Software Selection. 
IJAHP Article: Mu, Saaty/A Style Guide for Paper Proposals To Be Submitted to the International Symposium of the Analytic Hierarchy Process 2014, Washington D.C., U.S.A.

\section{Introduction}

Enterprise Resource Planning (ERP) is an emerging business concept for integrating all departments and business processes of a company into a single computer system that can serve all company requirements. This concept is widely accepted by various type of industry nowadays due to highly competitive business atmosphere that force any company to improve their business processes and business goals through any means including the advance of their information technology. During the implementation of ERP in any company, one of the most important issues is the selection of ERP software that can satisfy the needs and objectives of the company. This issue is crucial since it may affect the duration of ERP implementation and the costs incurred for the ERP implementation.

\section{Literature Review}

Parthasarathy (2007) stated that there are three different perspectives should be considered during the ERP software selection, which are business, technological, and organizational perspectives. Some researchers already used some criteria based on business and technological perspectives such as Wei et al. (2005), Ayag and Ozdemir (2007), Kahraman et al. (2010), Lin et al. (2011). The literatures show that organizational perspective has not been included yet in the selection criteria.

\section{Hypotheses/Objectives}

This research tries to construct a model of the selection of ERP software that are beneficial to the company in order to carry out the selection of the right ERP software vendors according to the needs and objectives of the company. The proposed ERP software selection model is constructed based on business, technology, and organizational perspectives. Since this problem of ERP software selection is involving many criteria and there exist dependency among criteria, therefore, the ERP software selection model is constructed based on the Analytic Network Process methodology.

\section{Research Design/Methodology}

The proposed ANP model for selecting ERP software is developed based existing literature review on ERP software selection and considering some inputs from experts from an automotive finance company in Indonesia. The criteria exist in the literature for selecting ERP software are listed. Based on the discussion with the experts, some criteria are selected and grouped into three clusters, which are business perspective, technological perspective, and organizational perspective. The ANP network structure of this problem are then developed based on the inner and outer dependence among criteria. An example of ERP software selection based on the experts' experience in their company is being used for illustrative purpose. The illustrative example is solved following ANP methodology assisted by Super Decision software.

\section{Data/Model Analysis}

The proposed ERP software selection model is built over four clusters, which are business perspective, technological perspective, organizational perspective, and vendor alternative. business perspective cluster consists of four criteria, which are cost, quality, vendor status, and customization. Technological perspective cluster consists of four International Symposium of 2 Washington, D. C. the Analytic Hierarchy June 29 - July 2, 2014 
IJAHP Article: Mu, Saaty/A Style Guide for Paper Proposals To Be Submitted to the International Symposium of the Analytic Hierarchy Process 2014, Washington D.C., U.S.A.

criteria, which are functionality, duration of implementation, user friendliness, and software update. Organizational perspective cluster consists of four criteria, which are training, employee needs, company culture, and human resistance. Vendor alternative cluster consists of alternatives of vendor, namely vendor A, B, and C. The network structure of criteria within the proposed ERP software selection model is presented in Figure 1.

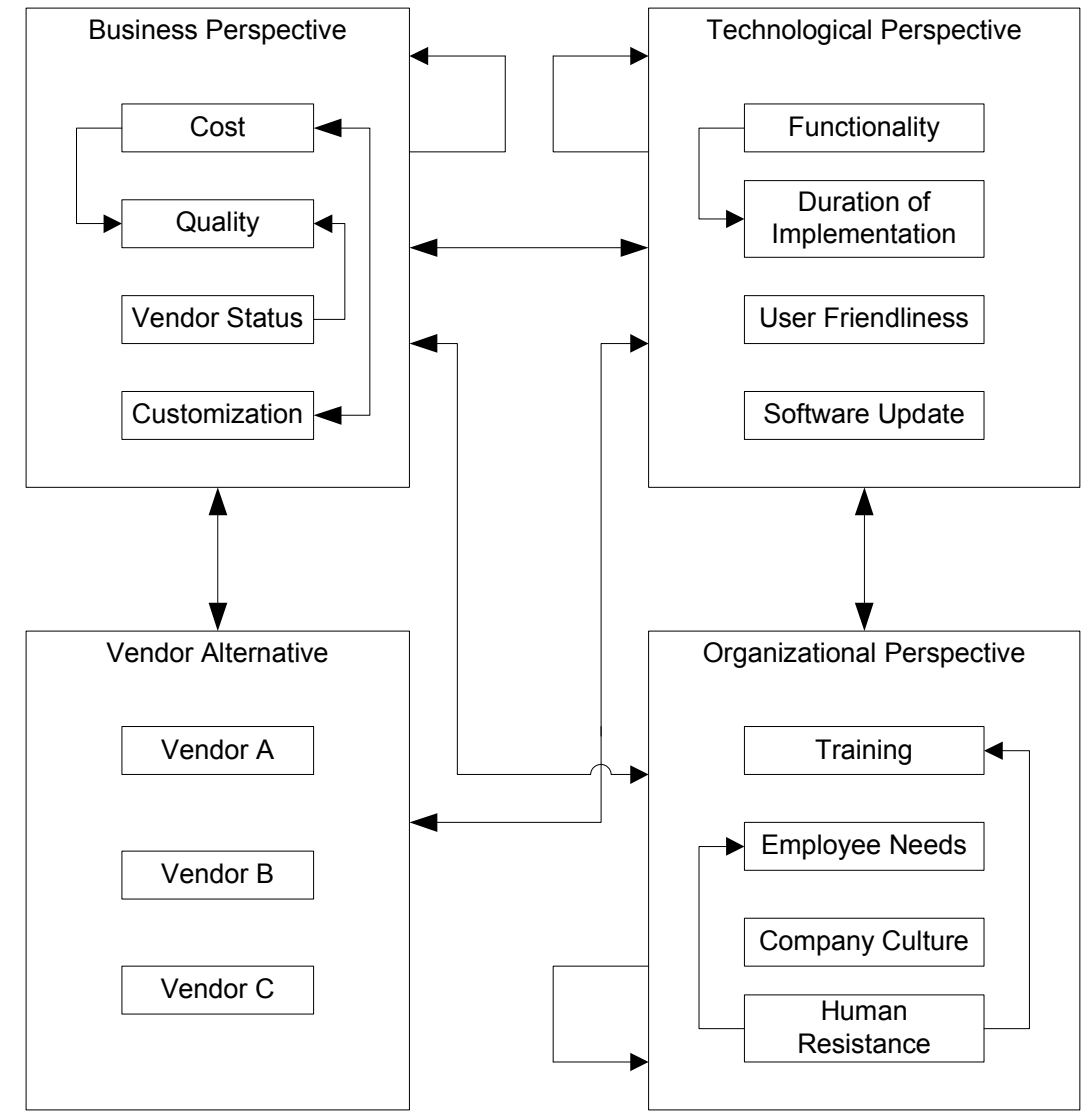

Figure 1 Network structure of ERP software selection model

Following the ANP methodology, finally, at the synthesis step the raw, normalized, and ideals values of each vendor alternative are presented in Table 1.

Table 1

Synthesis results of ERP software selection model

\begin{tabular}{llll}
\hline Vendor Alternative & Raw & Normalized & Ideals \\
\hline Vendor A & 0.0166 & 0.5320 & 1 \\
Vendor B & 0.0062 & 0.1987 & 0.3734 \\
Vendor C & 0.084 & 0.2692 & 0.5060 \\
\hline
\end{tabular}


IJAHP Article: Mu, Saaty/A Style Guide for Paper Proposals To Be Submitted to the International Symposium of the Analytic Hierarchy Process 2014, Washington D.C., U.S.A.

\section{Conclusions}

This research is able to build an ERP software selection model based on ANP method. The ERP software selection model comprises of four clusters, which are business perspective, technological perspective, organizational perspective, and vendor alternative. From an illustrative example from an automotive finance company in Indonesia, it is found that the ideal value for vendor $\mathrm{A}$, vendor $\mathrm{B}$, and vendor $\mathrm{C}$, are $1,0.3734$, and 0.5050 , respectively. This synthesis result show that the vendor $\mathrm{A}$ is the best ERP software for this company.

This research should be extended to various type of industry, so that the ERP software selection model can be generalized.

\section{Key References}

Ayag, Z., \& Ozdemir, R.G. (2007). An intelligent approach to ERP software selection through fuzzy ANP. International Journal of Production Research, 45(10), 2169-2194.

Karahman, C., Beskeye, A., \& Kaya, I. (2010). Selection among ERP outsourcing alternative using a fuzzy multi-criteria decision making methodology. International Journal of Production Research, 48(2), 547-566.

Lin, C.T., Chen, C.B., \& Ting, Y.C. (2011). An ERP model for supplier selection in electronics industry. Expert System with Application, 38, 1760-1765.

Parthasarathy, S. (2007). Enterprise Resource Planning (ERP) - A Managerial and Technical Perspective. New Delhi: New Age International.

Wei, C.C., Chien, C.F., \& Mang, M.J. (2005). An AHP-based approach to ERP system selection. International Journal of Production Economics, 96, 47-62. 